\title{
Debates culturales a través de Twitter
}

Las redes sociales están adquiriendo una relevancia cada vez mayor y no sólo a nivel personal, sino también profesional. Esta nueva forma de interacción ha generado importantes cambios en nuestros hábitos, promoviendo que acciones que hasta hace poco tiempo eran exclusivas del entorno presencial ahora ganen peso en el ámbito virtual. Un ejemplo de ello son los debates culturales, que han encontrado en Twitter un medio eficaz para desarrollarse y llegar a mayor cantidad de personas.

M. a Soledad Gómez Vílchez | MediaMusea: Museos, patrimonio cultural y tecnología

URL de la contribución <www.iaph.es/revistaph/index.php/revistaph/article/view/3548>

El ser humano es un animal social por naturaleza, defendió Aristóteles; por ello nos desarrollamos y crecemos como personas en entornos sociales, generamos comunidades y buscamos activamente medios para comunicarnos. Hoy esto se hace especialmente significativo por la gran penetración de la tecnología y las redes sociales en nuestras vidas, lo que ha favorecido tanto la proliferación de nuevos espacios de interacción como el hecho de que muchos de los ámbitos tradicionales de socialización ahora tengan lugar en un entorno virtual.

El cambio de hábitos en la sociedad genera un modelo de comunicación global, abierto y descentralizado. Ya no sólo queremos saber qué está pasando, sino que además nos interesa opinar sobre ello y conocer la impresión de los demás al respecto.

Entre las diferentes redes sociales existentes, Twitter se ha convertido en herramienta de información y de comunicación en masa. Es un espacio de conversación rápido y directo que ha demostrado su versatilidad y viralidad, así como su capacidad para ser un medio de debate y movilización. Su efecto está también presente en el ámbito cultural, donde el uso extensivo de esta red supone la involucración de las instituciones en el diálogo abierto, la visibilidad para el sector profesional y la participación directa del usuario.

La interacción social que se desarrolla en Twitter ha dado lugar a un modelo horizontal de comunicación en el que todos los entes que forman parte de la cultura (estudiantes, profesionales, empresas, instituciones...) dialogan a nivel de igualdad. Esto ha favorecido que sea un medio óptimo para el debate cultural.

Los debates a través de esta red social se caracterizan por una serie de elementos clave:

> Un tema común agrupado bajo un hashtag específico, en ocasiones acompañado de otros complementarios.

> Una cuenta principal moderadora, que, a modo de marca paraguas, centra la acción.

$>$ Varias cuentas dinamizadoras, que suelen corresponder a perfiles personales involucrados de forma más o menos directa.

$>$ La colaboración de diversos prescriptores culturales en el desarrollo de la iniciativa.

$>$ El apoyo de una web complementaria para recoger toda la información sobre el evento.

$>$ El registro, a modo de resumen, de los tuits y de los principales contenidos tratados una vez acabado el debate, bien en la web complementaria o a través de medios como Storify.

El germen de los debates culturales en Twitter se sitúa en el año 2010, con \#AskaCurator, propuesta liderada por Jim Richardson que tenía como objetivo que el público pudiera charlar directamente con los conservadores de museos y obtener respuestas a sus dudas y 


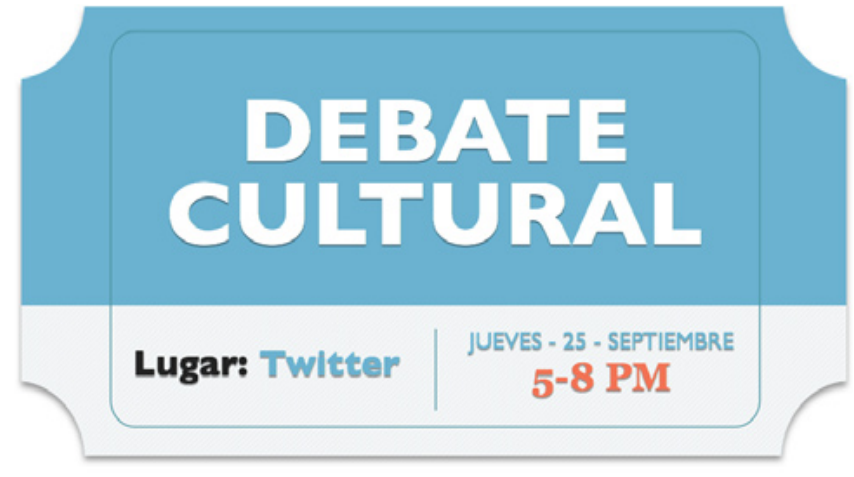

Twitter se ha convertido en un aliado para la cultura, generando una trama social no jerárquica | imágenes M. ${ }^{a}$ Soledad Gómez

curiosidades. Esta acción supuso en aquel momento un gran cambio en la forma de comunicar de las instituciones culturales, fundamentalmente unidireccional y con una baja interacción con sus seguidores.

En esta primera edición participaron un total de 343 museos y espacios culturales de 23 países. El hashtag \#AskaCurator se convirtió en el primer Trending Topic cultural a nivel mundial y la iniciativa fue recogida por numerosos medios de comunicación.

Dos años después, en 2012, volvía a repetirse esta convocatoria, ahora bajo el título Ask a Curator Day, con un cambio significativo en relación a los museos españoles participantes. En primer lugar, aumentaron de 11 a 36 los espacios culturales inscritos en la jornada; y en segundo lugar, los museos no asumieron únicamente una actitud pasiva, sino que incentivaron el diálogo y motivaron a los miembros de su comunidad para interactuar con ellos.

Pero esta iniciativa se basaba en un formato de preguntas/ respuestas y aunque en ocasiones generó conversación, en general era un modelo poco abierto al diálogo grupal.

El evento tuvo lugar de nuevo en 2013 y 2014 con una acogida más discreta, fundamentalmente porque tanto los museos como los usuarios han asumido la interacción como algo habitual y los centros son hoy más proclives a atender a diario las dudas de su comunidad.

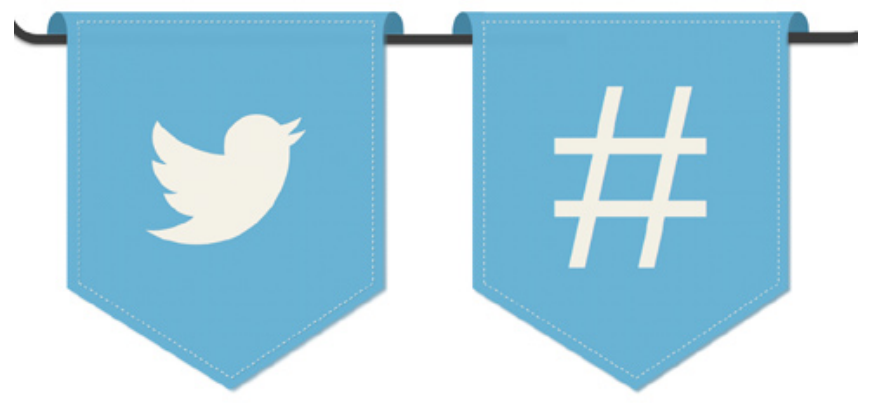

En España, el verdadero cambio a la hora de entender Twitter como un medio para el debate cultural vino de la mano de \#Cultura18, una iniciativa que recogió de manera casual la necesidad del sector de reflexionar acerca de temas de actualidad y que tras más de dos años de evolución ya se ha convertido en una cita consolidada. El proyecto, ideado en primer lugar por Dolores Lobillo (@doloreslobillo), Pablo Suárez (@ Desde_Jocaya) y Rafael Rodríguez-Varo (@patrimoniored), y al que luego se sumó Mónica Castro (@mocadele), ha conseguido articular a la comunidad cultural online y generar un punto de encuentro virtual todos los lunes a las 18h.

La base de esta convocatoria se centra en promover el intercambio de opiniones sobre los diferentes temas que cada semana se van proponiendo y anunciando en su web; en la variedad y actualidad de los contenidos, con una visión amplia e integradora de la cultura, y en una comunicación abierta, informal y horizontal en la que diferentes instituciones y agentes culturales dialogan en condiciones de igualdad y respeto mutuo.

El modelo de debate en Twitter también ha sido promovido por parte de centros culturales, como es el caso del Instituto Andaluz de Patrimonio Histórico, que con motivo del Día de la Mujer 2013 organizó el coloquio en red \#Enredadasen $\mathrm{PH}$, con una cuenta institucional como perfil moderador y 10 prescriptoras culturales como cola- 


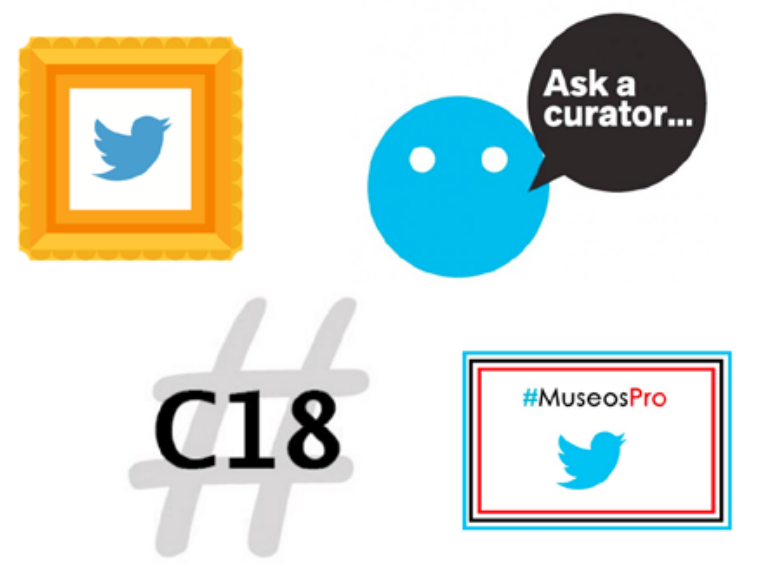

En España, el cambio a la hora de entender Twitter como un medio para el debate cultural vino de la mano de \#Cultura18 | imágenes M. ${ }^{a}$ Soledad Gómez

boradoras. Esta iniciativa pretendía dar visibilidad a las mujeres que trabajan en el campo del patrimonio, conocer sus experiencias y opiniones y generar un debate en torno a la profesión.

La importancia de la comunicación cultural a través de este medio se pone en evidencia con la iniciativa \#MuseumWeek, una semana dedicada a la interacción y diálogo con los museos europeos en Twitter que tuvo como punto destacado el hecho de ser promovida por la propia red social. En total fueron siete días, cada uno de ellos dedicado a una temática diferente y con un hashtag específico, en los que mostrar la historia de los museos, incentivar la creatividad, preguntar a los usuarios y, en definitiva, facilitar la interacción en este medio a través de contenidos específicos.

Museum Week implicaba conectar con el público del museo, pero en la comunidad profesional existe además una necesidad de reflexionar internamente acerca del estado de la profesión y una nueva acción, en este caso \#MuseosPro trataba de centrar el debate sobre formación, perfiles profesionales o formas de contratación. Coordinado por Laura Cano (@Via_di_uscita)y Almudena López (@alopezmolina), y con el apoyo de diversos colaboradores, este debate, que se desarrolló durante cuatro tardes a lo largo de junio de 2014, tenía como objetivo reflexionar sobre los temas que preocupan al sector profesional, conocer la opinión de

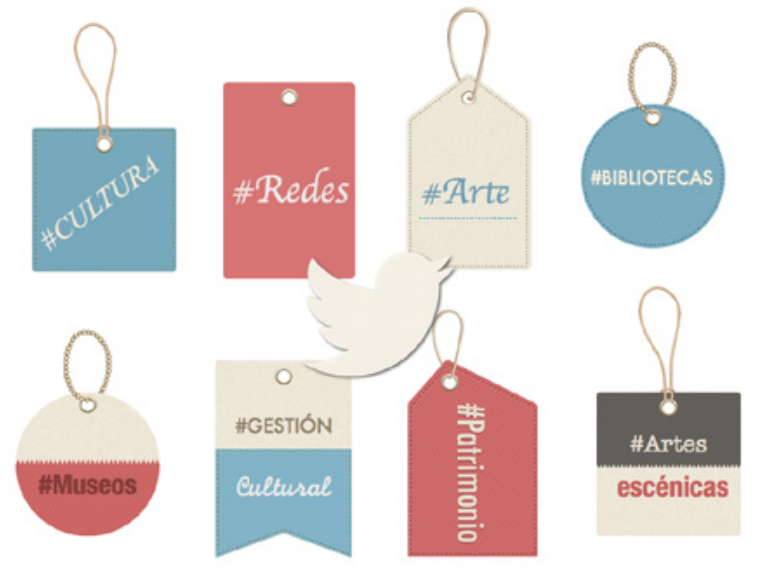

los trabajadores de las instituciones y orientar a estudiantes y desempleados en la búsqueda de oportunidades laborales.

Pero además de los ejemplos de debate que se desarrollan exclusivamente online, hoy es habitual que cualquier curso, congreso o evento presencial tenga a su vez su réplica a través de Twitter, propiciando un coloquio virtual que permite complementar el discurso, conocer la opinión de los participantes y conectar a los usuarios que no se encuentran presentes.

En definitiva, Twitter se ha convertido en un aliado para la cultura, generando una trama social no jerárquica, abierta y nodal que crea comunidad y favorece el activismo y la participación de diversos tipos de usuarios. A través de este medio se desarrolla un modelo de interacción basado en el debate y el diálogo, que está aportando nuevas posibilidades a la comunicación cultural y al sector profesional. 